\title{
Item Analysis in Affect Measurement on Decision to Car Purchase using Rasch Model
}

\author{
Asri Rejeki \\ Faculty of Psychology, University of Muhammadiyah Gresik \\ rejeki.asri@yahoo.co.id \\ Siti Sulasmi \\ Faculty of Economy, Airlangga University \\ Tatik Suryani \\ Magister Management, STIE Perbanas Surabaya
}

\begin{abstract}
The present research is a preliminary study which aims at analyzing items on affect instrument when consumers purchased a car by using Rasch model. The number of respondents who participated in the study were 82 people. The consumers were those who had bought the car. The instrument developed in the study was used to measure responses given by the consumers after buying a car. The instrument was reported by using Lakert 5 scale. The results of the study showed the reliability of Alpha Cronbach which was .78. Calculation of differential item functioning (DIF) score reached above .05. The result of the test item dimensionality (DIM) raw score variance was 36\%; this affirmed that the items contain no other dimensions. Overall, this instrument is considered reliable to be used in measuring the factors affecting the decision to buy a car.
\end{abstract}

Keywords: Rasch model, affect

\section{INTRODUCTION}

Car ownership is important because convenient mass transportation is still not available in big cities and the distance between residences and destinations such as workplaces, schools, campuses are getting further. Cars are one of the tools of transportation that can support the mobility of individuals and families. In addition, most people assume that car ownership is identical with the economic establishment of individuals. Individuals who have worked or who run a business are said to be economically well-established if they own a car. As a rule, a new employee who rides a motorcycle in their daily life will begin to dream to buy a car when they have enough budget. For individuals who already have a car, they will try to buy a better car in the future.

In the present study, the consumers' behaviors toward car purchase are studied, particularly the purchase that requires high involvement and emotions of the consumers. Research on the affective factors that influence satisfactory decision making was previously conducted by Kardes, et al (2011). When choosing an alternative, customers are oftentimes faced with the utility function of the true product. The utility function describes the relative conditions of happiness, pleasure, or satisfaction which are derived from using the product (Kardes, Cronley, \& Cline, 2011). Based on this, the utility function will determine to what extent the pleasure obtained from the product as well as product attributes.

\section{OBJECTIVE}

This paper aims at analyzing the affective measuring items from the pilot project.

\section{THEORETICAL BACKGROUND}

The initial process where the customers choose one among the existing alternatives affects the products to be purchased. This was stated in the previous studies which confirmed that positive attitude affects the thinking process, solves problems, and makes decisions (Gardner, 1985; Isen A., 2001; Isen, 1984; Isen, 2000). When deciding what to buy, consumers are influenced by the positive features of the products being offered. The positive aspects can improve problem solving and decision-making skills. This will encourage the cognitive processes not only flexibly, but also innovatively, creatively, and efficiently (Isen, 2001). In their later research, Isen and Reeve (2005) concluded that positive feature may also affect intrinsic and extrinsic motivation, work behavior, and affect some aspects of self-regulation to consume as forward thinking and self-control (Isen \& Reeve, 2005) . Other studies suggest that it can also influence attention, perception, memory, and decision-making processes (Winkielman, Knutson, Paulus \& Trujillo, 2007).

Affective and cognitive refers to two types of mental responses that are shown to the consumer's stimuli and events in the environment. Affective refers to a person's feelings about stimuli and events, whether they like or dislike the product. Cognition refers to thinking, such as belief in a particular product (Peter \& Olson, 2010). Affective responses include comfortable or uncomfortable, and different intensity variations. The affects include: (1) a relatively intense emotion such as love or anger, (2) less powerful feelings such as satisfaction or frustration, (3) moods such as boredom or relaxation, and (4) attitudes toward products like McDonald's French fries.

Research conducted by Isen (2004) concluded that positive affective has a clear and strong influence on 
thinking and behavior, from generosity to helpful behavior and social behavior. It is also ranging from solving problems to making basic cognitive decisions and processes (Isen, 2004 in Haugtvedt, 2008).

The environment will affect the affective and cognitive systems of consumers. Affective responses include emotions, feelings, and mood interpreted by the cognitive system (for example, I do not like this insurance agent, because it is too serious). Then, based on this interpretation, the consumer makes a conclusion (i.e. I will not buy insurance from the seller). In addition, affective reactions can affect cognition when making decisions. As an example, when I am in a good mood, I would rather spend money (Peter \& Olson, 2010: 44).

Paul Ekman defined basic emotions as the feeling of anger, disgust, fear, pleasure, sadness, and shock.
While Zamuner (1998) identified emotions as the feeling of pleasure, love, peace, compassion, anxiety, boring, sad, shocked, scared and angry (Consoli, 2009).

According to Robert Plutchik (1997), primary emotions include anger and fear, sadness and pleasure, shock and waiting, disgust and acceptance. Furthermore, Bindu et al (2007) stated that based on emotional expression, emotions can be grouped as 22 segments: happy, proud, enthusiastic, happy, love, soft, ecstasy, lust, surprise, conform, bored, indifferent, disgust, fear, revenge, sad, hate, sadness, shame, sad, angry (Consoli, 2009).

There are several tools to measure affect developed by several researchers.

Table 1: Affect scale

\begin{tabular}{|c|c|c|c|}
\hline No. & Author & Item & Validity and reliability \\
\hline & $\begin{array}{l}\text { Watson, Clark, } \\
\text { Tellegen } \\
\text { (1988) } \\
\text { PANAS }\end{array}$ & $\begin{array}{l}\text { Scared, afraid, upset, distressed, jittery, nervous, ashamed, guilty, } \\
\text { irritable, hostile, panicky, trouble, sad, worried, regretful, remorseful, } \\
\text { angry, edgy, depressed, uncomfortable, uneasy, tense. (negative } \\
\text { affect). } \\
\text { Enthusiastic, interested, determined, excited, inspired, alert, active, } \\
\text { strong, proud, attentive, aroused, thrilled. (positive affect). }\end{array}$ & $\begin{array}{l}\text { Crobach alpha positive affect }: .89 \\
\text { Negative affect : } 0.85\end{array}$ \\
\hline & $\begin{array}{l}\text { Carroll dan } \\
\text { Ahuvia (2006), } \\
\text { Love brand }\end{array}$ & $\begin{array}{ll}\text { 1. } & \text { This is a wonderful brand. } \\
2 . & \text { This brand makes me feel good. } \\
3 . & \text { This brand is totally awesome. } \\
\text { 4. } & \text { I have neutral feelings about this brand (reverse-coded } \\
\text { item). } & \\
5 . & \text { This brand makes me very happy. } \\
6 . & \text { I love this brand. } \\
7 . & \text { I have no particular feeling about this brand. } \\
8 . & \text { This brand is a pure delight. } \\
9 . & \text { I am passionate about this brand. } \\
\text { 10. } & \text { I am very attached to this brand. }\end{array}$ & \\
\hline & 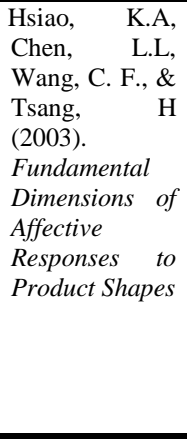 & $\begin{array}{l}\text { Avant-grade - conservative } \\
\text { Excited - calm } \\
\text { Contemporary - traditional } \\
\text { Futuristic - nostalgic } \\
\text { Old - young } \\
\text { Innovative - imitiative } \\
\text { Dazzling - ordinary } \\
\text { Heavy - light } \\
\text { Strong - weak } \\
\text { Feminine - masculline } \\
\text { Cute - not cute } \\
\text { Rational } \quad \text { emotional } \\
\text { Soft - hard } \\
\text { Simple } \quad \text { complex }\end{array}$ & \\
\hline
\end{tabular}

A positive affect improves problem-solving skills and enhances decision-making skills, which in turn will drive the cognitive process not only flexible, innovative, and creative, but also efficient. Positive affects also affect the consumer's potential reaction to advertising, products, consumptive situations, and services (Isen, 2001: 75). A positive affective is considered a process. Djamasbi (2007) tested the positive affective role on the use of decision support systems. The results of the study showed that positive affects increase the number of signs and accuracy of the judgments one makes in making decisions (Lewis, Haviland-Jones, Jeannette M, \& Feldman, 2008). 


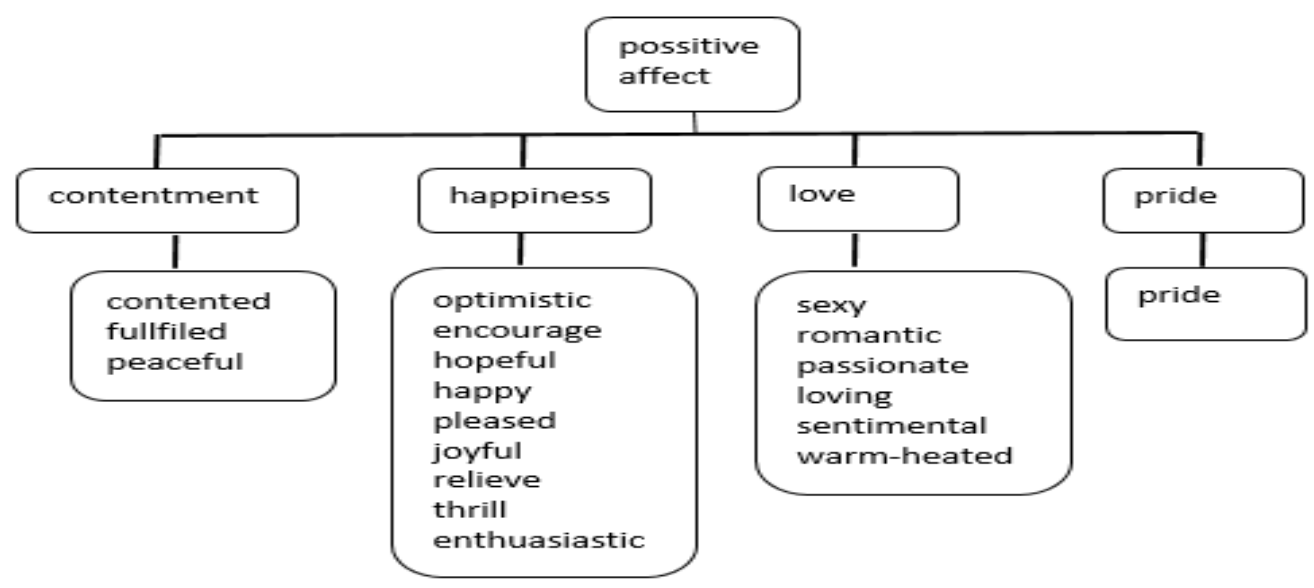

Figure 1 : positive affect hierarchy

Source : Laros, F. J., \& Steenkamp, J.B. E. ( 2005). Emotions in Consumer Behavior : a Hirarchical Approach. Journal of Business Research, 58 (10), 1437 - 1445.(Fleurr J.M. Steenkamp \& E.M, 2005)

Some studies have shown the affective effects on behavior and thought processes, including memory, decision making, risk preferences, problem solving and creativity (Isen 2000, in Isen \& Reeve, 2006).

Emotional conditions can have a biased effect on costumers' decision-making. Consumers do not look good at assigning judgments and integrating multidimensional information. When consumers confront information in various forms, they typically rely on few factors and simplify considerations rather than having to thoroughly evaluate in detail (Nisbett \&
Ross, 1980; Slovak, Fischoff \& Lichtensein, 1977; Tversky \& Kahneman 1974 in Bandura 1997). Research done by Luce et al (1997) found that choice-making would be difficult and emotionally burdensome to consumers when they had to decide between options that were of value according to their original goals (Luce, Bettman, \& Payne, 1997). However, Kardes (2011) asserted that positive affects may help consumers make better decisions and be more satisfied in making decisions to buy (Kardes, Cronley, \& Cline, 2011).

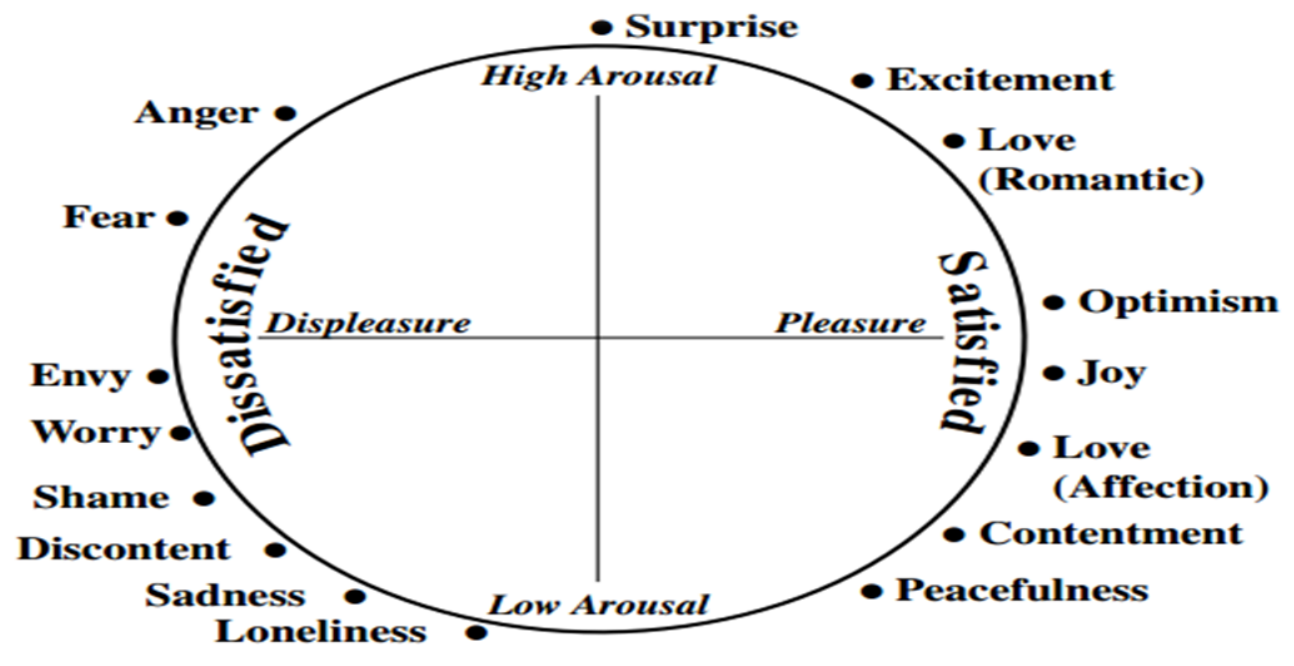

Figure 2: Affect on consumen emotion set

Source : Richard L. Oliver (2015). Satisfaction : A Behavioral Perspective on the Consumer $2^{\text {nd }}$ ed. London Routledge Taylor \& Francis Group 
Figure 2 shows affects on consumers. Consumers who are satisfied with levels from neutral to high arousal and from neutral to pleasure are optimistic, love, excitement, and surprise. In contrast, consumers who are satisfied with the level of neutral to low arousal and from neutral to pleasure (pleasure) is joy, love (affection), contentment, peacefulness.

Consumers who are dissatisfied with the condition from neutral to high arousal and from neutral to displeasure are anger and fear. While consumers who are not satisfied with the low

arousal condition from neutral to high arousal and from neutral to displeasure are envious, worry, shame, discontent, sad, and lonely.

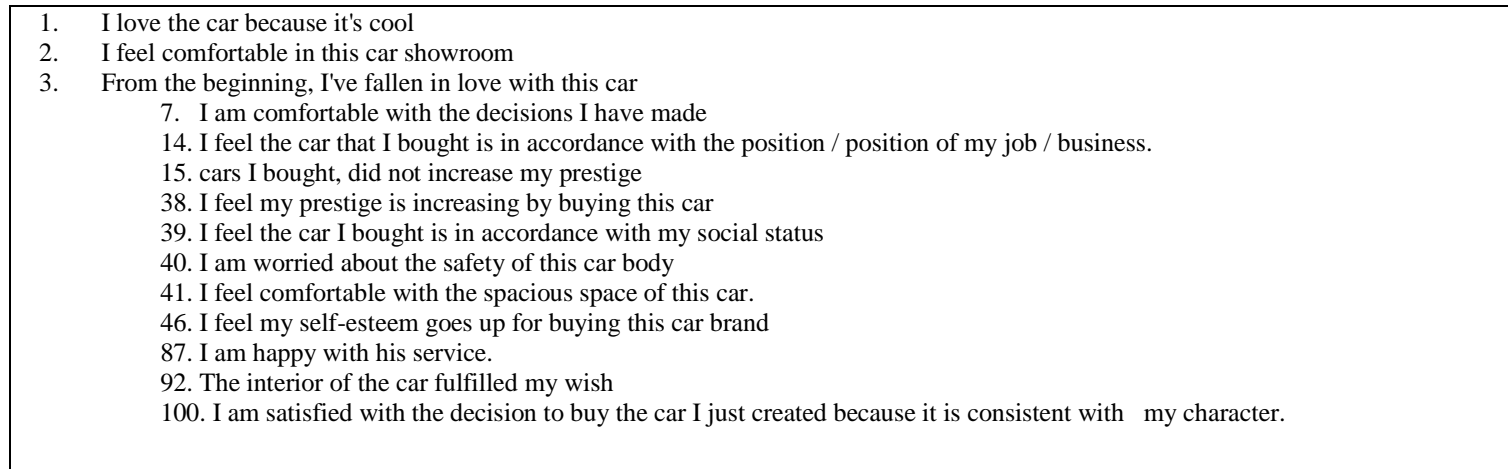

\section{DISCUSSION}

Based on the results of the analysis, it appears that by doing the cleaning data, the researcher can change the outlier items to become fit. In addition, it can increase the item reliability from .92 to .93 and reliability person from .77 to .79 . Cronbach alpha reliability score is .78 , indicating the items in this instrument has a good reliability when used. The highest logit score on item number 15 indicates the item with the highest difficulty level for respondents to approve the statement. The item is "the car I bought did not increase my prestige". While the lowest logit score is on item number 7 . The easiest item for the respondent to approve the statement. The item is "I feel comfortable with the decision I've made". The DIF (Differential Item Functioning) score is all above .05, which indicates that the existing item does not contain bias over the respondent's characteristics. Characteristics of respondents include gender, education, tribe, and income. So it can be concluded that the item is able to apply generally. A DIM (Item Dimentionality) score of $36 \%$ indicates the item does not contain any other dimensions. Affect items are able to measure affects and no other dimensions that enter in affects. Based on the picture of the variable map, it is apparent that there is a uniform distribution of the items which means the item has varying difficulty level so that it can be said good item to measure the affects.
The model illustrates how the circle affects consumers in a complex continuum, with levels from low arousal to high arousal, and from levels of not satisfied to highly satisfied. This model can explain how affective consumers affect satisfactory in decision making. Based on theory and previous research, researcher develop some scales below. 